\title{
Communications
}

\section{Anion Triggered Supramolecular Topological Change from a Coordination Polymer to a Dumbbell}

\author{
Ki-Hyun Kim, ${ }^{\dagger}$ Raju Nandhakumar, ${ }^{\dagger}$ Youngmee Kim, ${ }^{\dagger}$ Sung-Jin Kim, ${ }^{\dagger}$ Moo-Jin Jun, ${ }^{\ddagger, \xi, *}$ and Kwan Mook Kim ${ }^{\dagger, *}$ \\ †Department of Chemistry \& Division of Nano Sciences, Ewha Womans University, Seoul 120-750, Korea \\ *E-mail:kkmook@ewha.ac.kr \\ ¿Department of Chemistry, Yonsei University, Seoul 120-749, Korea \\ ${ }^{\S}$ KISTI ReSEAT program senior fellow, Korea Institute of Science and Technology Information, Seoul 130-742, Korea \\ Received February 14, 2011, Accepted March 27, 2011
}

Key Words : Molecular dumbbell, Supramolecule, Topological change, Self-assembly

Supramolecular self-assembly is a bottom-up approach leading to nano-structures with well-defined molecular arrangements, and has created a huge number of coordination polymers and cages in the past decades. ${ }^{1-3}$ At the same time, many supramolecular dumbbells produced by self-assembly processes have also been documented. ${ }^{4}$ Signal changes or topological changes by a particular guest increases the utility of supramolecules in molecular sensing and molecular machine chemistry. ${ }^{5,6}$ Our laboratory reported previously the studies on the molecular recognition of Inorganic Tennis Balls (ITBs) and its extended structures produced by bridging it with 4,4'-bipyridine (bpy). ${ }^{7}$ The selfassembly of (dach) $\mathrm{Pt}^{\mathrm{II}}(\mathrm{DTEYM})$ with $\mathrm{Cu}(\mathrm{OTf})_{2}$ in methanol gives the ITB- $\mathbf{1}^{4+}$, [[\{(dach)Pt(DTEYM $\left.\left.\left.)\right\}_{2} \mathrm{Cu}\right]_{2}\right]^{4+}$, with interior empty cavity, which is known to encapsulate anions such as $\mathrm{Cl}^{-}, \mathrm{NO}_{3}{ }^{-}$and $\mathrm{ClO}_{4}{ }^{-8} \cdot{ }^{-}$In addition, the ITB-1 ${ }^{4+}$ has two exterior pockets recognizing pyridine-like molecules, and thus bridging of ITB-1 ${ }^{4+}$ with bpy leads to 1-D array, $\left(\right.$ bpy-ITB- $\left.1^{4+}\right){ }^{7}$ Herein we report the transformation of the 1-D array to molecular dumbbell triggered by the presence of a particular anion, perchlorate.

The crystallization of (dach) $\mathrm{Pt}^{\mathrm{II}}(\mathrm{DTEYM})$ and $\mathrm{Cu}\left(\mathrm{ClO}_{4}\right)_{2}$ in methanol is known to give ITB-2 ${ }^{3+}$, with a chemical formula of $\left[\left[\{(\text { dach }) \operatorname{Pt}(\mathrm{DTEYM})\}_{2} \mathrm{Cu}\right]_{2}\left(\mathrm{ClO}_{4}\right)\right]^{3+}$, which has one $\mathrm{ClO}_{4}{ }^{-}$in the interior cavity. ${ }^{8}$ We obtained crystals ${ }^{9,10}$

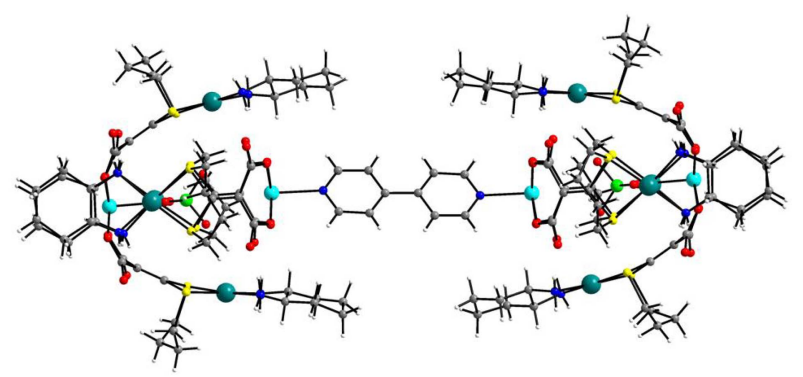

Figure 1. Ball and stick representation of the crystal structure of $[\text { bpy-(ITB-2) })_{2}^{6+}$ with supramolecular dumbbell shapes. from the mixture of ITB-2 $2^{3+}$ and excess bpy in methanol, whose structure is shown in Figure 1. Two unis of ITB-2 ${ }^{3+}$ are connected by one bpy through $\mathrm{Cu}-\mathrm{N}$ coordination bond. Among the two copper ions only one in each ITB-2 ${ }^{3+}$ is coordinated to the bpy. Hence, the shape of the two ITBs bridged by a bpy appears like a molecular dumbbell. This is a remarkable topological variation compared to the 1-D array of the self-assembly product between ITB-1 ${ }^{4+}$ and bpy.

The topological variation induced by the anion change from $\mathrm{OTf}^{-}$to $\mathrm{ClO}_{4}^{-}$is associated with coordination ability of copper(II) ion. Some copper(II) carboxylate complexes are known to adopt square-pyramidal geometry. ${ }^{11}$ The inside of the cavity of ITB- $\mathbf{1}^{4+}$ is empty, thus the both copper ions in one ITB-1 ${ }^{4+}$ molecule could coordinate to bpy molecules adopting a square-planar geometry. ITB-2 ${ }^{3+}$, however, has the cavity filled by $\mathrm{ClO}_{4}^{-}$anion, which allows only one copper ion to coordinate to a bpy molecule. The copper that is not bound to bpy could coordinate to $\mathrm{ClO}_{4}{ }^{-}$anion inside the cavity and both copper ions could keep 5-coordinations. Figure 2 shows selected crystal structure around $\mathrm{ClO}_{4}{ }^{-}$anion inside the cavity, where among four oxygen atoms of $\mathrm{ClO}_{4}{ }^{-}$ anion only one oxygen, $\mathrm{O}(18)$, is close to $\mathrm{Cu}(2)$ atom by 2.688(14) ^.

Figure 3(a) shows partial ${ }^{1} \mathrm{H}$ NMR spectrum at the
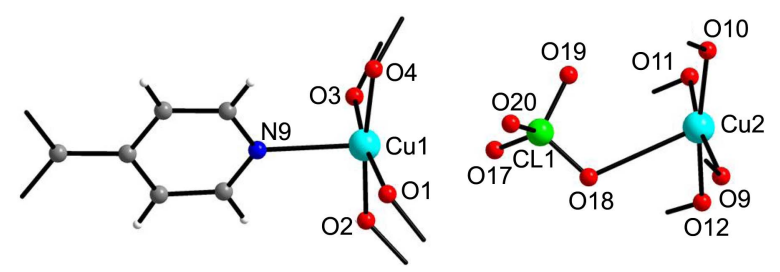

Figure 2. Partial crystal structure around the $\mathrm{ClO}_{4}{ }^{-}$anion inside the cavity of $[\text { bpy-(ITB-2) }]^{6+}$. Interatomic distances $(\AA)$ : $\mathrm{Cu}(1)-\mathrm{N}(9)$ 2.341(9), $\mathrm{Cu}(1)-\mathrm{O}(1)$ 1.954(9), $\mathrm{Cu}(1)-\mathrm{O}(2)$ 1.952(8), $\mathrm{Cu}(1)-\mathrm{O}(3)$ 1.935(9) $\mathrm{Cu}(1)-\mathrm{O}(4)$ 1.942(8), $\mathrm{Cu}(2)-\mathrm{O}(9)$ 1.930(10), $\mathrm{Cu}(2)-\mathrm{O}(10)$ 1.930(9), $\mathrm{Cu}(2)-\mathrm{O}(11)$ 1.928(10), $\mathrm{Cu}(2)-\mathrm{O}(12)$ 1.938(9); $\mathrm{Cu}(2)-$ $\mathrm{O}(18) 2.688(14), \mathrm{Cu}(2)-\mathrm{O}(19) 3.025(15), \mathrm{Cu}(1)-\mathrm{O}(17) 3.281(17)$, $\mathrm{Cu}(1)-\mathrm{O}(20) 3.211(14)$. 


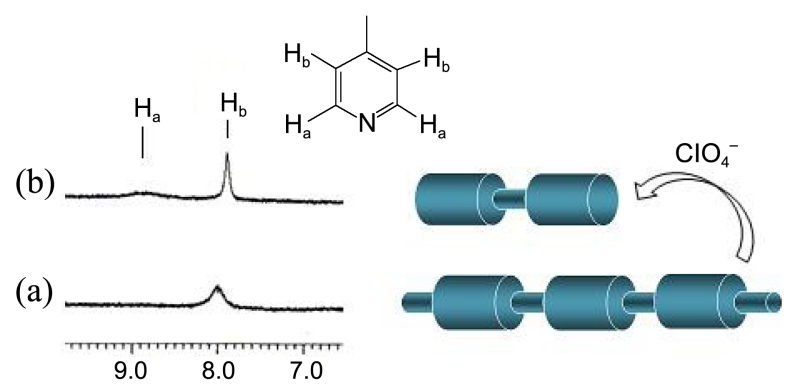

Figure 3. (a) Partial ${ }^{1} \mathrm{H}$ NMR spectrum at the region of bpy ligand for the methanol- $d_{6}$ solution of ITB-1 ${ }^{4+}$ and bpy. (b) The partial ${ }^{1} \mathrm{H}$ NMR spectrum obtained after the addition of 1 equivalent $\mathrm{ClO}_{4}{ }^{-}$ anion. The spectra indicate the change of the ITB-bpy supramolecule from polymeric to dumbbell nature.

aromatic region for the methanol- $d_{6}$ solution of ITB- $\mathbf{1}^{4+}$ and bpy. The coordination of nitrogen to copper(II) atom broadens the peak of the proton at ortho position $\left(\mathrm{H}_{\mathrm{a}}\right)$, and the peak for $\mathrm{H}_{\mathrm{a}}$ is hardly seen. When 1 equivalent $\left[\mathrm{Bu}_{4} \mathrm{~N}\right]\left[\mathrm{ClO}_{4}^{-}\right]$ is added to the solution of Figure 3(a), the spectrum of Figure 3(b) is obtained. The appearance of the $\mathrm{H}_{\mathrm{a}}$ peak reveals that the bpy is binding to copper less strongly due to the encapsulation of the $\mathrm{ClO}_{4}^{-}$anion in the cavity of ITB$\mathbf{1}^{4+}$. Certainly, the $\mathrm{ClO}_{4}^{-}$anion in the cavity makes one copper to lose the power of binding affinity toward the pyridine nitrogen as discussed in the fore section.

In conclusion, we have shown that the polymeric supramolecule formed by ITB- $\mathbf{1}^{4+}$ and bpy is transformed to a dumbbell-shaped supramolecule by the addition of $\mathrm{ClO}_{4}{ }^{-}$ anion. The crystal structure of the supramolecular dumbbell prepared from the solution of ITB-2 ${ }^{3+}$ and bpy shows that the encapsulation of $\mathrm{ClO}_{4}^{-}$anion in the cavity of ITB is a key factor inducing the formation of the dumbbell.

Acknowledgments. This research was supported by the Ministry of Science and Technology of Korea through NRL (2010-0008022), SRC program of NRF at Ewha Womans University (2011-0001334) and RP-Grant 2010 of Ewha Womans University. One of the authors, M.-J. Jun, is grateful to the KISTI ReSEAT program for the support.

\section{References}

1. (a) Swiegers, G. F.; Malefetse, T. J. Chem. Rev. 2000, 100, 3483. (b) Khlobystov, A. N.; Blake, A. J.; Champness, N. R.; Lemenovskii, D. A.; Majouga, A. G.; Zyk, N. V.; Schröder, M. Coord. Chem. Rev. 2001, 222, 155. (c) James, S. L. Chem. Soc. Rev. 2003, 32, 276. (d) Kitagawa, S.; Kitaura, R.; Noro, S. Angew. Chem. Int. Ed. 2004, 43, 2334. (e) Fujita, M.; Tominaga, M.; Hori, A.;
Therrien, B. Acc. Chem. Res. 2005, 38, 369.

2. Atwood, J. L.; Davies, J. E. D.; MacNicol, D. D.; Vögtle, F. Comprehensive Supramolecular Chemistry; Vol. 9, Pergamon: Oxford, 1996

3. (a) Janzen, D. E.; Patel, K. N.; VanDerveer, D. G.; Grant, G. J. Chem. Commun. 2006, 3540. (b) Yaghi, O. M.; O'Keeffe, M.; Ockwig, N. W.; Chae, H. K.; Eddaoudi, M.; Kim, J. Nature 2003, 423, 705. (c) Ma, L.-F.; Wang, L.-Y.; Huo, X.-K.; Wang, Y.-Y.; Fan, Y.-T.; Wang, J.-G.; Chen, S.-H. Cryst. Growth Des. 2008, 8, 620. (d) Huang, Y.-Q.; Cheng, P. Inorg. Chem. Commun. 2008, 11, 66.

4. (a) Min, K. S.; Suh, M. P. J. Am. Chem. Soc. 2000, 122, 6834. (b) Park, K.-M.; Moon, S.-T.; Kang, Y. J.; Kim, H. J.; Seo, J.; Lee, S. S. Inorg. Chem. Commun. 2006, 9, 671. (c) Janzen, D. E.; Chen, W.; VanDerveer, D. G.; Mehne, L. F.; Grant, G. J. Inorg. Chem. Commun. 2006, 9, 992. (d) Lee, S. Y.; Park, S.; Seo, J.; Lee, S. S. Inorg. Chem. Commun. 2007, 10, 1102.

5. (a) Kang, H. J.; Noh, T. H.; Jin, J. S.; Jung, O.-S. Inorg. Chem. 2008, 47, 5528. (b) Noh, T. H.; Moon, S. J.; Na, Y. M.; Ha, B. J.; Jung, O.-J. Inorg. Chem. Commun. 2008, 11, 1334. (c) Jo, M.; Seo, J.; Seo, M. L.; Choi, K. S.; Cha, S. K.; Lindoy, L. F.; Lee, S. S. Inorg. Chem. 2009, 48, 8186. (d) Nanda, K. K.; Addison, A. W.; Butcher, R. J.; McBevit, M. R.; Rao, T. N.; Sinn, E. Inorg. Chem. 1997, 36, 134.

6. (a) Taylor, M. K.; Trotter, K. D.; Reglinski, J.; Berlouis, L. E. A.; Kennedy, A. R.; Spickett, C. M.; Sowden, R. J. Inorg. Chim. Acta 2008, 361, 2851. (b) Sarkar, S.; Patra, A.; Drew, M. G. B.; Zangrando, E.; Chattopadhyay, P. Polyhedron 2009, 28, 1. (c) Malachowski, M. R.; Adams, M.; Elia, N.; Rheingold, A. L.; Kelly, R. S. J. Chem. Soc., Dalton Trans. 1999, 2177. (d) Musker, W. K.; Olmstead, M. M.; Kessler, R. M. Inorg. Chem. 1984, 23, 1764.

7. (a) Kim, K.-H.; Song, R.; Kim, K. M. J. Am. Chem. Soc. 2003, 125, 7170. (b) Oh, K.; Lee, H.; Kim, K.-H.; Kim, Y. S.; Nam, W.; Kim, K. M. Bull. Kor. Chem. Soc. 2007, 28, 2193.

8. Kim, K.-H.; Park, J. S.; Kang, T. Y.; Oh, K.; Seo, M.-S.; Sohn, Y. S.; Jun, M.-J.; Nam, W.; Kim, K. M. Chem. Eur. J. 2006, 12, 7078.

9. Synthesis of [bpy-(ITB-2 $\left.)_{2}\right]\left(\mathrm{ClO}_{4}\right)_{6}$. [ITB-2] $\left(\mathrm{ClO}_{4}\right)_{3}(0.27 \mathrm{~g}, 0.10$ $\mathrm{mmol})$ and bpy $(0.080 \mathrm{~g}, 0.50 \mathrm{mmol})$ were dissolved in methanol $(5 \mathrm{~mL})$ in a $10 \mathrm{~mL}$ vial, and the solution was placed in room temperature for one month. Single crystals of block shape grown were collected, washed with cold methanol and dried in vacuo. Yield: $58 \%$ based on ITB-2. Anal. Calc. for [bpy-(ITB-2 $\left.)_{2}\right]\left(\mathrm{ClO}_{4}\right)_{6}$, $\mathrm{C}_{122} \mathrm{H}_{184} \mathrm{Cl}_{8} \mathrm{Cu}_{4} \mathrm{~N}_{18} \mathrm{O}_{64} \mathrm{Pt}_{8} \mathrm{~S}_{16}$ : C, 26.5; H, 3.35; N, 4.55\%. Found: C, 26.7; H, 3.38; N, 4.55\%. IR (solid $\mathrm{KBr}$ pellet, $\mathrm{v} / \mathrm{cm}^{-1}$ ): 3410 (br), 3215 (s), 3126 (s), 3035 (s), 2937 (s), 2888 (s), 1627 (vs), 1445 (m), 1376 (vs), 1123 (vs), 760 (m), 628 (s).

10. Crystal data for [bpy-(ITB-2 $\left.)_{2}\right]\left(\mathrm{ClO}_{4}\right)_{6}: \mathrm{C}_{122} \mathrm{H}_{184} \mathrm{Cl}_{8} \mathrm{Cu}_{4} \mathrm{~N}_{18} \mathrm{O}_{64} \mathrm{Pt}_{8} \mathrm{~S}_{16}$, $0.10 \times 0.08 \times 0.08 \mathrm{~mm}^{3}, \mathrm{FW}=5339.41, P-1, a=15.640(3), b=$ $17.360(4), c=24.280(5) \AA, \alpha=76.18(3), \beta=86.13(3), \gamma=63.60(3)^{\circ}$, $V=5728(2) \AA^{3}, Z=1, \mu($ Mo-K $\alpha)=5.506 \mathrm{~mm}^{-1}, 32272$ measured reflections $[R($ int $)=0.0245]$ were used in all calculations, final $R$ $=0.0785(R w=0.2473)$ with reflections having intensities greater than $2 \sigma, \operatorname{GOF}\left(F^{2}\right)=1.067$. CCDC reference number CCDC798768.

11. Kolling, O. W.; Lambert, J. L. Inorg. Chem. 1964, 3, 202. 